\title{
Phage-based forensic tool for spatial visualization of bacterial contaminants in cheese
}

\author{
Sarah Kozak (i) and Samuel D. Alcaine* (1) \\ Department of Food Science, Cornell University, Ithaca, NY 14853
}

\section{ABSTRACT}

Traditional procedures for microbial testing typically involve a homogenizing step. These methods give valuable information on the presence or enumeration of a bacterial contaminant, but not where the contaminant was in the original sample. Spatial information could be useful in troubleshooting sources of bacterial contamination in a processing plant. For example, if the contaminant was localized on the top of a food such as cheese, this might indicate dripping condensate along a specific processing line as its source. The objective of this proof-of-concept study was to evaluate the use of a genetically engineered phage to detect bacterial contaminants on cheese to be able to visualize the contaminants without the use of magnification. In this study, a T7 bacteriophage engineered to overexpress the luciferase NanoLuc (Promega, Madison, WI) was utilized to reveal the spatial location of Escherichia coli on lysogeny broth (LB) agar and queso fresco (QF). Four scenarios were tested to explore how phage may be applied, with a blue bioluminescent signal revealing the spatial location of contaminants: (1) phage applied topically via molten soft agar to $E$. coli-inoculated (a) LB agar or (b) QF; and (2) phage incorporated within (a) LB agar or (b) QF and then inoculated with $E$. coli. Each was tested in triplicate. Cultures of E. coli BL21 grown for $18 \mathrm{~h}$ were serially diluted in phosphatebuffered saline and inoculated onto $8 \pm 0.5 \mathrm{~g}$ of $\mathrm{LB}$ agar or $\mathrm{QF}$ in 6-well plates. Plates were incubated at $37^{\circ} \mathrm{C}$ for $8 \mathrm{~h}$ for condition $1 \mathrm{a}, 24 \mathrm{~h}$ for $1 \mathrm{~b}$ and $2 \mathrm{~b}$, and $22 \mathrm{~h}$ for $2 \mathrm{a}$. For $1 \mathrm{a}$ and $1 \mathrm{~b}$, stock phage was added to molten soft agar, applied topically, and incubated for 2 additional hours to allow for E. coli infection. After incubation, the substrate NanoGlo (Promega) was added to cover the surface of the agar or cheese and imaged immediately in a dark box using a digital camera and long exposure to capture the bioluminescent signal.

Received October 28, 2019.

Accepted March 9, 2020.

*Corresponding author: alcaine@cornell.edu
Photographs captured small blue spots where the incubated colony-forming units were located. The lowest inoculum level of $E$. coli detected for each scenario was $1.43 \times 10^{1} \pm 9.94,1.18 \times 10^{1} \pm 7.07,5.48 \times 10^{1} \pm 1.19$ $\times 10^{1}$, and $2.37 \times 10^{1} \pm 1.40 \times 10^{1} \mathrm{cfu} /$ well, for $1 \mathrm{a}$, $1 \mathrm{~b}, 2 \mathrm{a}$, and $2 \mathrm{~b}$, respectively. These data demonstrate that the reporter phage proof-of-concept could be used as a forensic tool to visualize the spatial location of bacteria in a cheese matrix. Future work will translate this concept to dairy-relevant phage-pathogen systems. Key words: phage-based forensics, cheese, luciferase, NanoLuc

\section{INTRODUCTION}

In the dairy industry, microbial testing of cheese is performed routinely to maintain acceptable safety and quality. However, the majority of microbial testing requires homogenization of the cheese sample to release any bacteria into liquid (such as a buffer or enrichment broth) before detection (Hitchens et al., 2017). As a result, the presence or absence of a microbe can be detected, as well as enumerated in some cases; however, tools are scant that allow for information on exactly where the bacteria are located in a cheese.

In cheese, there are multiple foodborne pathogens where spatial information would be useful in troubleshooting contamination, including Salmonella spp., Escherichia coli, and Listeria monocytogenes. Although post-pasteurization contamination of cheese by Salmonella spp. and E. coli from the environment can happen, these pathogens are typically associated with dairy cattle and have been the source of foodborne illness outbreaks in raw milk cheeses, particularly outside the United States (Dominguez et al., 2009; Gaulin et al., 2012). Listeria monocytogenes can contaminate the incoming milk, a risk for raw milk cheeses (Lovett et al., 1987), and it is also a common post-pasteurization contaminant because of its ubiquity in the environment and its ability to both survive and grow at refrigeration temperatures (Rosso et al., 1996). Forensic tools can be used to determine the spatial location of these bacterial contaminants on cheese and ultimately pro- 
vide information about the source of contamination. For example, if $L$. monocytogenes are localized on the top of a cheese, it may indicate dripping condensate as the source of contamination, whereas finding L. monocytogenes within the cheese itself may be indicative of contamination during the cheesemake. This spatial information would then allow a producer to more rapidly determine where to focus their mitigation efforts, and perhaps focus environmental swabbing to identify and root out environmental sources of contamination. Bacteriophage (phage) represent a potential tool to enhance the spatial detection of bacteria. Phages replicate quickly and are host specific, and thus can be used to target undesirable bacteria in foods. Phages can be bioengineered to broaden their host range and to produce reporter enzymes that enhance visual detection methods (Alcaine et al., 2016). Thus, phages represent highly customizable tools that could be used to aid in the spatial detection of specific bacteria of concern.

The use of phages in bacterial detection systems is well documented (Hagens and Loessner, 2007). The use of phage as a detection tool is particularly advantageous due to the narrow host specificity and the ability to differentiate between live and dead cells. Furthermore, phage genomes can be genetically engineered to express reporter genes, including enzymes that produce bioluminescence, such as luciferases. A relatively new luciferase isolated from the deep-sea shrimp Oplophorus gracilirostris is commercially available as NanoLuc (Promega, Madison, WI). In the presence of the novel imidazopyrazinone substrate furimazine - commercially available from Promega as NanoGlo-a blue luminescent signal is produced that is stronger than that of other comparable luciferase systems (Hall et al., 2012) and can be visualized without the need for external light sources.

Here, we propose a proof-of-concept novel phage reporter system whereby the spatial location of bacterial contaminants can be visually detected without the use of magnification or additional light sources. In these experiments, we explored the use of a T7 phage engineered to produce NanoLuc fused to a carbohydrate-binding module (Hinkley et al., 2018) to detect Escherichia coli as a model of surface microbial contamination on agar and fresh cheese (queso fresco, QF). Lysogeny broth agar and cheese were first inoculated with the contaminant. Then, the cheese was incubated for a predetermined amount of time, allowing any cells present to grow and subsequently be infected by phages. Post-infection, cell lysis resulted in the release of the reporter (NanoLuc) into the system, at which point the addition of NanoGlo produced a bioluminescent signal showing spatially where the contaminant was located. The results are promising, showing that phage engineered to produce the reporter enzyme NanoLuc can be applied to a contaminated cheese and provide information on the spatial location of the contaminant. It highlights the need for further research in translating this phage-based system to target other cheese-relevant bacteria, such as L. monocytogenes-specific phages, to create novel tools that improve the ability to identify source of contamination.

\section{METHODS}

\section{E. coli Growth}

For all assays, E. coli BL21 competent cells were grown in lysogeny broth, Miller (LB; Becton Dickinson, Franklin Lakes, NJ). Single colonies were inoculated into $5 \mathrm{~mL}$ of LB and incubated aerobically with shaking at $200 \mathrm{rpm}$ for $18 \mathrm{~h}$ at $37^{\circ} \mathrm{C}$. Before use, cultures were serially diluted in PBS to reach desired inoculum levels ranging from $10^{0}$ to $10^{4} \mathrm{cfu} / \mathrm{mL}$. Dilutions were concurrently enumerated on LB agar and incubated at $37^{\circ} \mathrm{C}$ for $18 \mathrm{~h}$ to confirm inoculation rates ranging from $10^{0}$ to $10^{4} \mathrm{cfu} / \mathrm{mL}$.

\section{Phage Stock Preparation}

Bacteriophage T7 engineered to contain NanoLuc luciferase with a carbohydrate-binding module (nluc::cbm; $\mathbf{T} \mathbf{7}_{\mathrm{NLC}}$ ) were obtained from the Nugen Research group at Cornell University (Ithaca, NY; Hinkley et al., 2018). An overnight culture of $E$. coli $(100 \mu \mathrm{L})$ was inoculated into $50 \mathrm{~mL}$ of $\mathrm{LB}$ and incubated at $37^{\circ} \mathrm{C}$ aerobically with shaking at $200 \mathrm{rpm}$ for $1 \mathrm{~h}$ to bring cells into the logarithmic phase. Phage stock $(100 \mu \mathrm{L})$ was added to the LB, which was returned to the incubator for $2 \mathrm{~h}$ to allow phage to propagate. The suspension was then centrifuged at 3,220 $\times g$ (Centrifuge 5810R, Eppendorf, Hauppauge, NY) to remove E. coli cells, and the supernatant was further filtered through a $0.22-\mu \mathrm{m}$ cellulose acetate filter (Corning Inc., Corning, NY) to remove any remaining cells and debris. To remove background NanoLuc, $1 \mathrm{~g}$ of microcrystalline cellulose (Alfa Aesar, Haverhill, MA) was added to the filtrate and mixed on a rotator (Thermo Fisher Scientific, Waltham, MA) for $1 \mathrm{~h}$ to irreversibly bind the free-floating reporter. The solution was then filtered again through a $0.22-\mu \mathrm{m}$ filter to remove the cellulose and bound NanoLuc. The phage stock was titered using a standard plaque assay (Kropinski et al., 2009) and stored at $4^{\circ} \mathrm{C}$ until use.

\section{Experimental Design}

Assays were performed in 6-well multiwell plates (Corning, Tewksbury, MA). All assays were performed 
Table 1. Lowest level of Escherichia coli inoculum detected by $\mathrm{T} 7_{\mathrm{NLC}}{ }^{1}$ following optimized incubation at $37^{\circ} \mathrm{C}^{2}$

\begin{tabular}{|c|c|c|c|}
\hline Phage application & Growth matrix & $\begin{array}{l}\text { Incubation time } \\
\text { for } E \text {. coli growth }(\mathrm{h})\end{array}$ & $\begin{array}{l}\text { Lowest inoculum level } \\
\text { of } E \text {. coli } \text { detected }(\mathrm{cfu} / \text { well } \pm \mathrm{SEM})\end{array}$ \\
\hline Topical & Lysogeny broth agar & 8 & $1.43 \times 10^{1} \pm 9.94$ \\
\hline Incorporated & Lysogeny broth agar & 24 & $1.18 \times 10^{1} \pm 7.07$ \\
\hline Incorporated & Laboratory-scale queso fresco & 24 & $2.37 \times 10^{1} \pm 1.11 \times 10^{1}$ \\
\hline
\end{tabular}

${ }^{1} \mathrm{~T} 7_{\mathrm{NLC}}=\mathrm{T} 7$ bacteriophage engineered to overexpress the luciferase NanoLuc (Promega, Madison, WI).

${ }^{2}$ Values reflect the average lowest inoculum level detected over at least 3 replicates. Inoculum levels were confirmed via plating on lysogeny broth agar.

in triplicate with biological replicates. Inoculation of various $E$. coli concentrations was randomized using a sequence generator (https://www.random.org/) to account for potential spatial bias during imaging. In each 6 -well plate, 5 of the 6 wells were inoculated with E. coli, and 1 well was inoculated with PBS as a negative control. Four scenarios were tested to explore how phage may be applied, with a blue bioluminescent signal revealing the spatial location of contaminants: (1) phage applied topically via molten soft agar to $E$. coli-inoculated (a) LB agar or (b) QF; and (2) phage incorporated within (a) LB agar or (b) QF, and then inoculated with $E$. coli. Incubation times were deter- mined in preliminary experiments (data not shown) and reflect the amount of time needed for E. coli to enter into the logarithmic phase, thus allowing for phage infection to occur.

\section{Imaging}

Imaging was performed using a Canon EOS Rebel T6 camera (Canon Inc., Tokyo, Japan). Camera settings were chosen to capture the bioluminescent signaling: manual focus, shutter speed of $30 \mathrm{~s}$, and ISO 6000 . Plates were imaged inside a dark box covered with a blackout curtain to minimize outside light exposure.
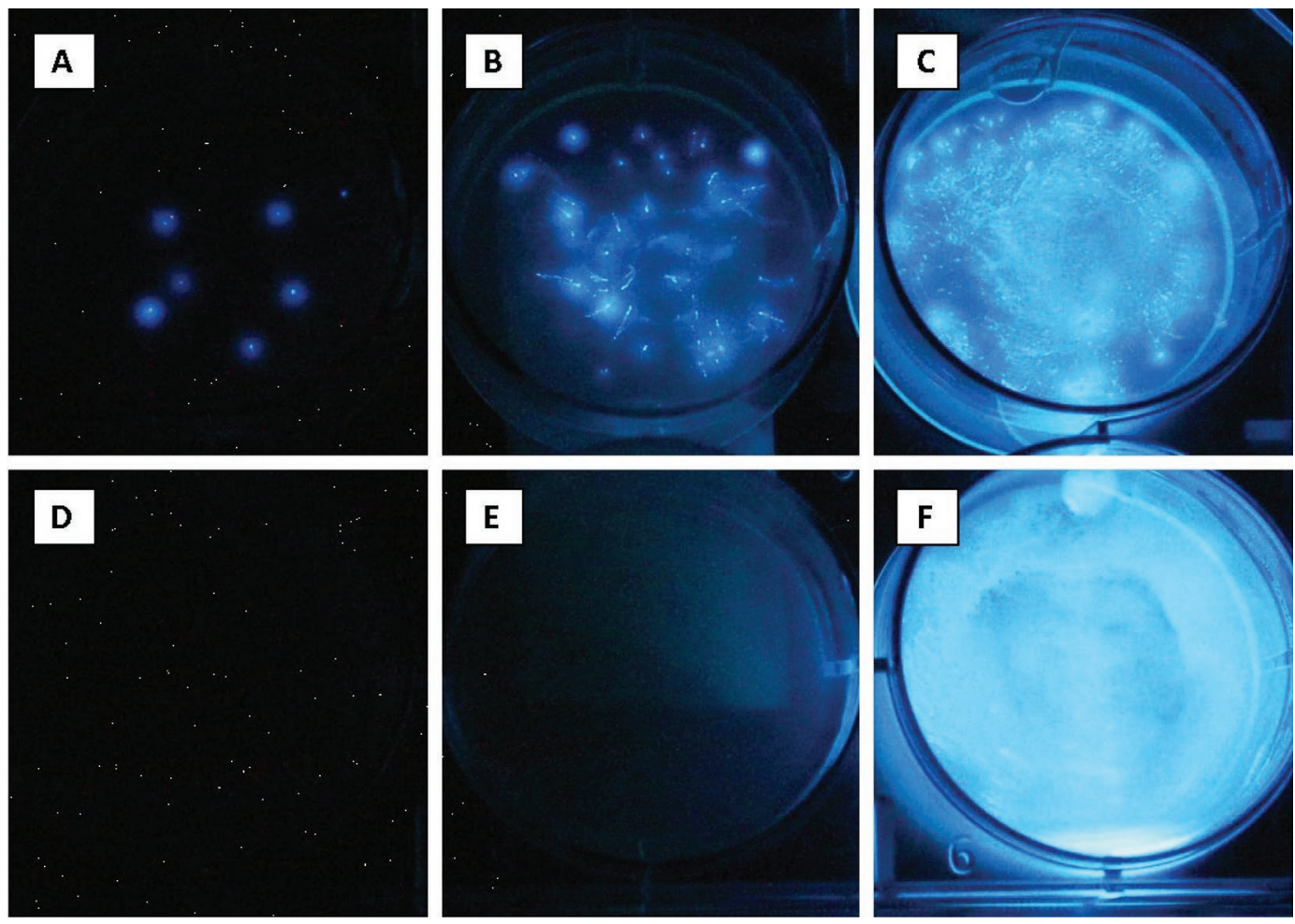

Figure 1. Detection of Escherichia coli BL21 inoculated onto lysogeny broth (LB) agar in a 6-well plate. The $\mathrm{T} 7_{\mathrm{NLC}}$ phage (T7 bacteriophage engineered to overexpress the luciferase NanoLuc; Promega, Madison, WI) were applied at $1 \times 10^{6}$ plaque-forming units (pfu)/mL topically via molten soft agar. Approximate E. coli inoculation levels, per well, based on serial dilution on LB agar: $(\mathrm{A}) 4.6 \times 10^{0} \mathrm{cfu},(\mathrm{B}) 4.6 \times 10^{1} \mathrm{cfu},(\mathrm{C})$ $4.6 \times 10^{2} \mathrm{cfu}$, (D) $0 \mathrm{cfu},(\mathrm{E}) 4.6 \times 10^{-1} \mathrm{cfu}$, and $(\mathrm{F}) 4.6 \times 10^{3} \mathrm{cfu}$. 


\section{Phage Applied Topically to Surface-Inoculated LB Agar}

Molten LB agar was aseptically transferred to multiwell plates ( $8 \mathrm{~mL}$ per well) and allowed to solidify overnight. Wells were inoculated with $10 \mu \mathrm{L}$ of culture, which was spread evenly over the agar using a sterile loop. Plates were incubated for a total of $8 \mathrm{~h}$ at $37^{\circ} \mathrm{C}$. After incubation, $\mathrm{T} 7_{\mathrm{NLC}}$ was added to each well in 300 $\mu \mathrm{L}$ of molten soft agar $\left(0.75 \%\right.$ agar, $\left.50^{\circ} \mathrm{C}\right)$ containing $1 \times 10^{6}$ plaque-forming units $(\mathbf{p f u}) / \mathrm{mL}$ within the soft agar. Plates were incubated for 2 additional hours to allow for phage infection. NanoGlo was added $(100 \mu \mathrm{L} /$ well) and plates were imaged immediately.

\section{Phage Added to Molten LB Agar Before Surface-Inoculation}

Stock $\mathrm{T} 7_{\mathrm{NLC}}$ was added to molten $\mathrm{LB}$ agar $\left(50^{\circ} \mathrm{C}\right)$ to achieve a concentration of $1 \times 10^{6} \mathrm{pfu} / \mathrm{mL}$, which was aseptically transferred to multiwell plates $(8 \mathrm{~mL}$ per well) and allowed to solidify. Wells were inoculated with $10 \mu \mathrm{L}$ of culture spread evenly over the agar using a sterile loop. Plates were incubated for $24 \mathrm{~h}$ at $37^{\circ} \mathrm{C}$.
NanoGlo was added (100 $\mu \mathrm{L} /$ well) and plates were imaged immediately.

\section{Phage Applied Topically to Surface-Inoculated GF}

Commercial QF (Emmi Roth, Monroe, WI) was cut into pieces of $8 \pm 0.5 \mathrm{~g}$ and placed into 6 -well plates. The, $100 \mu \mathrm{L}$ of $E$. coli was inoculated onto the surface and plates were incubated at $37^{\circ} \mathrm{C}$ for $22 \mathrm{~h}$. After incubation, excess whey was removed to prevent pooling, and $\mathrm{T} 7_{\mathrm{NLC}}$ was added to each cheese sample via $300 \mu \mathrm{L}$ of molten soft agar $\left(0.75 \%\right.$ agar, $\left.50^{\circ} \mathrm{C}\right)$ containing $1 \times$ $10^{6} \mathrm{pfu} / \mathrm{mL}$ within the soft agar. Plates were incubated for 2 additional hours to allow for phage infection. NanoGlo was added (100 $\mu \mathrm{L} /$ well $)$ and plates were imaged immediately.

\section{Phage Added to Milk Before Cheesemake and Surface-Inoculation}

Queso fresco was prepared on a laboratory scale (Lawton et al., 2020). The cheesemake began in 1-L bottles containing $600 \mathrm{~mL}$ of nonhomogenized whole milk heated to $35^{\circ} \mathrm{C}$. First, $\mathrm{T} 7_{\mathrm{NLC}}$ was incorporated into
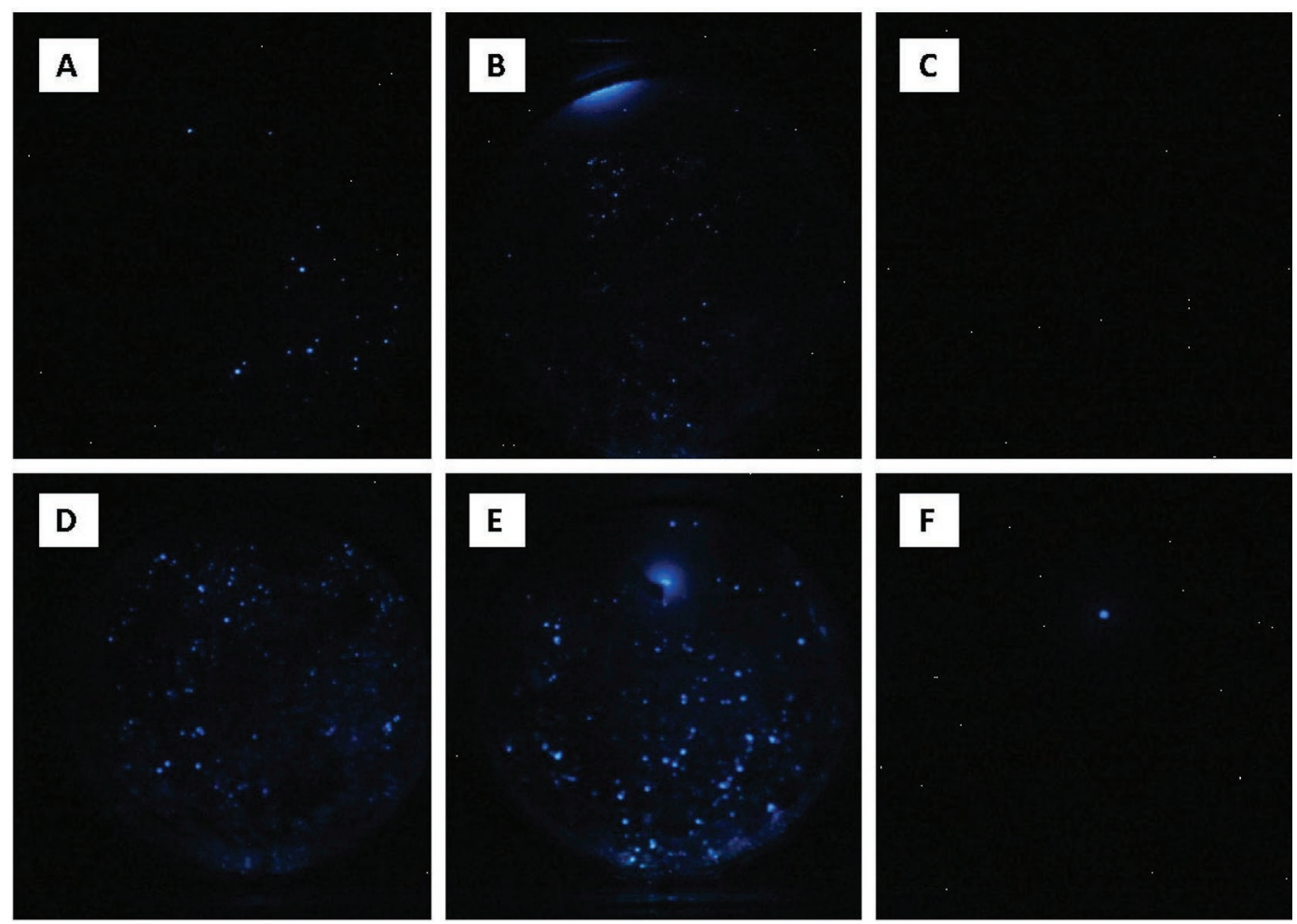

Figure 2. Detection of Escherichia coli BL21 inoculated onto lysogeny broth (LB) agar in a 6-well plate. The T7 $7_{\mathrm{NLC}}$ phage (T7 bacteriophage engineered to overexpress the luciferase NanoLuc; Promega, Madison, WI) were incorporated within agar at $1 \times 10^{6}$ plaque-forming units (pfu)/ $\mathrm{mL}$. Approximate E. coli inoculation levels, per well, based on serial dilution on LB agar: (A) $5.7 \times 10^{1} \mathrm{cfu},(\mathrm{B}) 5.7 \times 10^{4} \mathrm{cfu},(\mathrm{C}) 0 \mathrm{cfu},(\mathrm{D})$ $5.7 \times 10^{3} \mathrm{cfu},(\mathrm{E}) 5.7 \times 10^{2} \mathrm{cfu}$, and $(\mathrm{F}) 5.7 \times 10^{0} \mathrm{cfu}$. 
the milk to achieve a concentration in the milk of 1 $\times 10^{6} \mathrm{pfu} / \mathrm{mL}$. Then, $804 \mu \mathrm{L}$ of a 32 to $33 \% \mathrm{CaCl}_{2}$ solution (Dairy Connection Inc., Madison, WI) and $6 \mathrm{~mL}$ of deionized water solution containing $90 \mu \mathrm{L}$ of double-strength rennet (Chy-Max Extra, Chr. Hansen, Milwaukee, WI) were added. Bottles were swirled to mix and the contents poured into plastic cheese vats. The vats were incubated at $35^{\circ} \mathrm{C}$ in a water bath for $45 \mathrm{~min}$. The curd was cut and incubated for $15 \mathrm{~min}$, during which time the temperature was increased to a final temperature of $40^{\circ} \mathrm{C}$ (increased at $1^{\circ} \mathrm{C} / 3 \mathrm{~min}$ ). For salt addition, $60 \mathrm{~mL}$ of whey was removed and replaced with $60 \mathrm{~mL}$ of an aqueous $\mathrm{NaCl}$ solution $(0.16 \mathrm{~g} / \mathrm{mL})$ and stirred to mix. The vats were incubated at $40^{\circ} \mathrm{C}$ for another $20 \mathrm{~min}$. The curds were transferred to sterile cheesecloth and drained for $1 \mathrm{~h}$. Then, $15 \mathrm{~g}$ of curd was scooped into each well of a 6 -well plate (Corning Inc., Corning, NY). The curd was pressed for $2 \mathrm{~h}$, giving a final cheese with a weight of $\sim 13 \mathrm{~g}$. Cheese was stored at $4^{\circ} \mathrm{C}$ until ready for inoculation. For inoculation, 100 $\mu \mathrm{L}$ of $E$. coli was spotted onto the surface and plates were incubated at $37^{\circ} \mathrm{C}$ for $24 \mathrm{~h}$. After incubation, excess whey was removed, NanoGlo was added $(100 \mu \mathrm{L} /$ well), and plates were imaged immediately.

\section{Spot-Inoculation of Commercial QF}

Wheels of commercial QF (La Morenita Brands, Madison, WI) were spot-inoculated with $10 \mu \mathrm{L}$ of $E$. coli. The culture was diluted in PBS dyed with red food coloring to visualize the location where the inoculum was originally spotted. Wheels were placed in a biosafety cabinet to allow the inoculum to attach for 1 $\mathrm{h}$ before incubating at $37^{\circ} \mathrm{C}$ for $18 \mathrm{~h}$. Two milliliters of molten top agar containing $1 \times 10^{6} \mathrm{pfu} / \mathrm{mL}$ of $\mathrm{T} 7_{\mathrm{NLC}}$ was added to the surface of the cheese, and wheels were incubated for 2 more hours to allow for phage infection. NanoGlo was added to the surface $(500 \mu \mathrm{L})$ and the cheese was imaged immediately.

\section{RESULTS AND DISCUSSION}

In industrial applications, approved phage (generally recognized as safe by the Food and Drug Administration) may be applied either to a food surface through a method such as spraying (Tomat et al., 2013) or added within if the food matrix allows for phage to be mixed in homogeneously, such as with the addition to milk for use in cheese (García et al., 2007). Current appli-
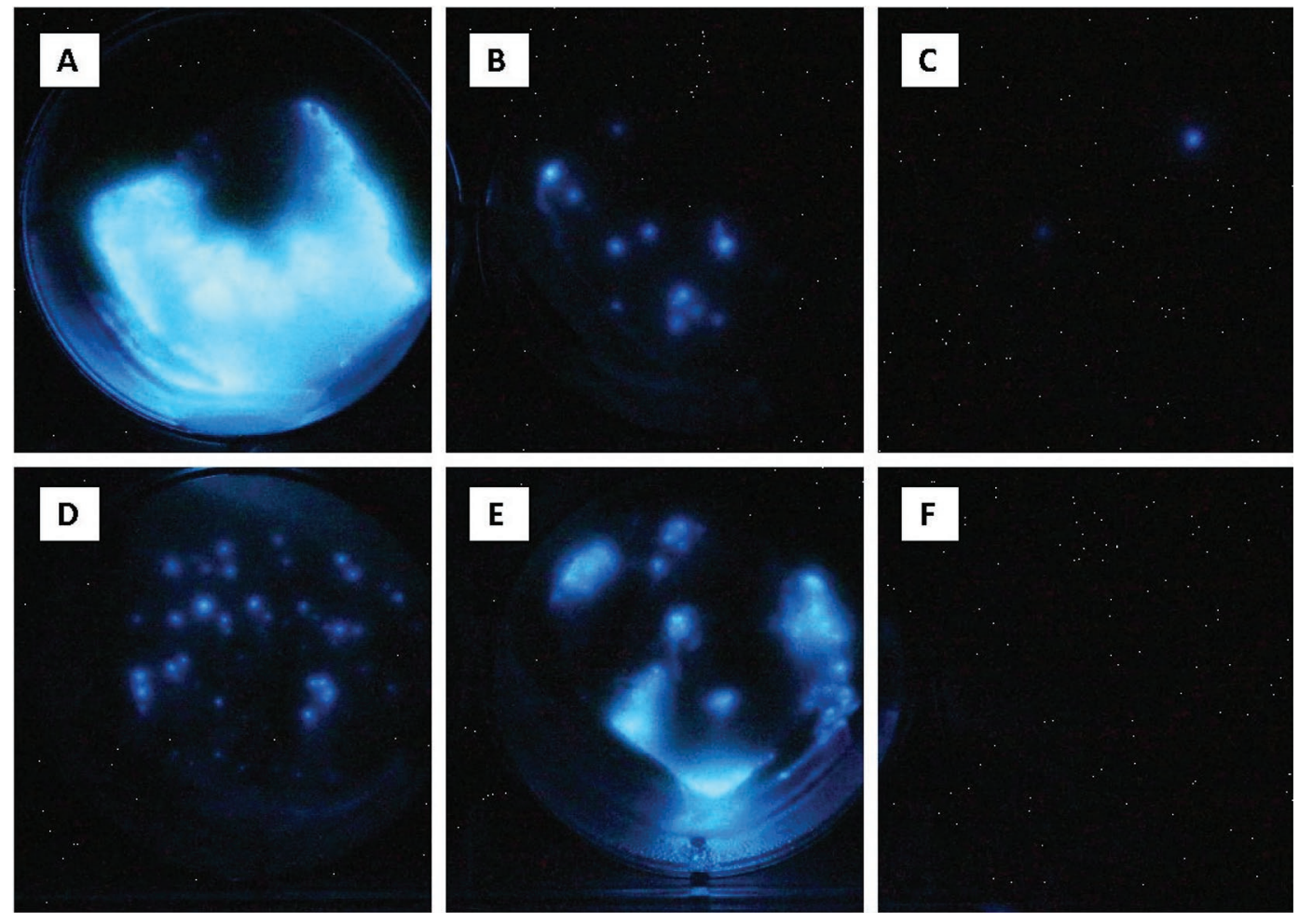

Figure 3. Detection of Escherichia coli BL21 inoculated onto queso fresco in a 6 -well plate. The T7 $7_{\mathrm{NLC}}$ phage (T7 bacteriophage engineered to overexpress the luciferase NanoLuc; Promega, Madison, WI) were applied at $1 \times 10^{6}$ plaque-forming units (pfu)/mL topically via molten soft agar. Approximate E. coli inoculation levels, per well, based on serial dilution on lysogeny broth agar: (A) $6.4 \times 10^{4} \mathrm{cfu},(\mathrm{B}) 6.4 \times 10^{1} \mathrm{cfu},(\mathrm{C})$ $6.4 \times 10^{0} \mathrm{cfu},(\mathrm{D}) 6.4 \times 10^{2} \mathrm{cfu},(\mathrm{E}) 6.4 \times 10^{3} \mathrm{cfu}$, and (F) $0 \mathrm{cfu}$. 
cations mainly use phage as an antimicrobial agent, because bacteria die after phage infection; however, the commercial use of bioengineered phage for pathogen detection in dairy products has begun (Arias-Rios et al., 2019). Here, $\mathrm{T} 7_{\mathrm{NLC}}$ was applied both topically and internally in both LB agar and QF to explore potential application methods of phage in a cheese matrix for the purpose of determining the location of bacterial contaminants.

The objective of the first set of experiments using LB agar as a growth matrix (1a and $1 \mathrm{~b}$ ) were to explore differences in visualization and detection level when $\mathrm{T} 7_{\mathrm{NLC}}$ was added topically versus internally. Furthermore, we wanted to see if individual colony-forming units could be visualized without the use of magnification or additional light sources. Although detection limits were similar, in that both methods allowed visualization of E. coli inocula less than $20 \mathrm{cfu}$, the time needed to incubate plates to visualize the inoculum varied (Table 1 ). When phage were applied within the agar, incubation time increased by $16 \mathrm{~h}$. This difference can most likely be attributed to cells lysing early on during incubation when phage are already present in the agar matrix versus being applied topically in top agar after the bacteria have had time to grow. In both scenarios, individual colonies could be seen without magnification by the emission of the blue bioluminescent signal indicative of $E$. coli infection by $\mathrm{T} 7_{\mathrm{NLC}}$ (Figures 1 and 2).

In the second set of experiments, phage were applied topically to and within QF. Across replicates, the lowest level of inoculum detected consistently ranged between 10 and 100 cells. Visualization of E. coli inoculated on QF (Figure 3) was similar to that seen using LB agar, with individual colony-forming units indicated by small blue dots. When phage were added to milk in the cheesemaking process, visualization of individual colony-forming units was less defined because of whey expulsion during incubation. As seen in Figure 4, the bioluminescent signal, although strong, is seen throughout the cheese. Depending on the dairy product and its moisture, wheying off may present a challenge. NanoLuc is produced wherever live bacteria are infected by phage, and the bioluminescent signal appears where the NanoLuc is acting. With wheying off, the liquid may transport the NanoLuc to a different area than where the bacteria are located, producing an inaccurate indication of where the bacteria are spatially located. Therefore, the incorporation of appropriate absorbents
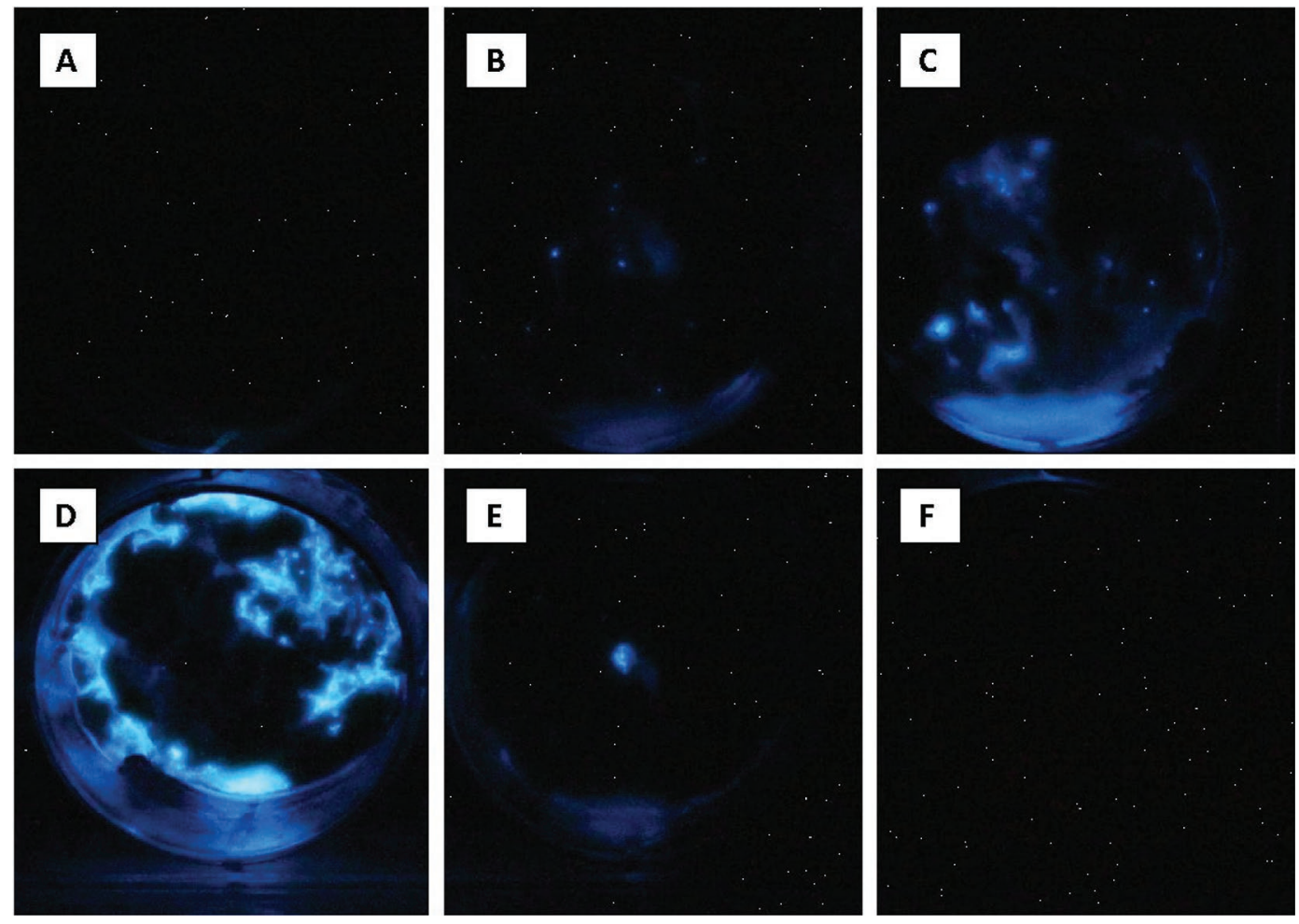

Figure 4. Detection of Escherichia coli BL21 inoculated onto queso fresco in a 6 -well plate. The T7 $7_{\mathrm{NLC}}$ phage (T7 bacteriophage engineered to overexpress the luciferase NanoLuc; Promega, Madison, WI) were applied within milk before cheesemaking at $1 \times 10^{6}$ plaque-forming units $(\mathrm{pfu}) / \mathrm{mL}$. Approximate E. coli inoculation levels, per well, based on serial dilution on lysogeny broth agar: $(\mathrm{A}) 6.7 \times 10^{-1} \mathrm{cfu},(\mathrm{B}) 6.7 \times 10^{1}$ cfu, (C) $6.7 \times 10^{2} \mathrm{cfu},(\mathrm{D}) 6.7 \times 10^{3} \mathrm{cfu},(\mathrm{E}) 6.7 \times 10^{0} \mathrm{cfu}$, and $(\mathrm{F}) 0 \mathrm{cfu}$. 
to prevent whey flow and improve signal localization will need to be investigated.

The purpose of the final experiment, utilizing an uncut, commercial wheel of QF, was to emphasize that the specific location of the contaminant can be seen when using this phage-reporting system. As seen in Figure 5a, the E. coli were inoculated near the center of the cheese (red spot). Phage was added over the entire top of the wheel. However, after incubation and addition of NanoGlo, the bioluminescent signal was seen only at the exact location of inoculation. This indicates that not only can the $\mathrm{T} 7_{\mathrm{NLC}}$ phage be used to detect a bacterial contaminant, but the location of the contaminant can also be determined. Further, it highlights the specificity of the system.

These experiments demonstrate a proof-of-concept of the potential of reporter phage to detect microbes in cheese and other dairy foods. Although detection methods of bacterial contaminants in the dairy industry are
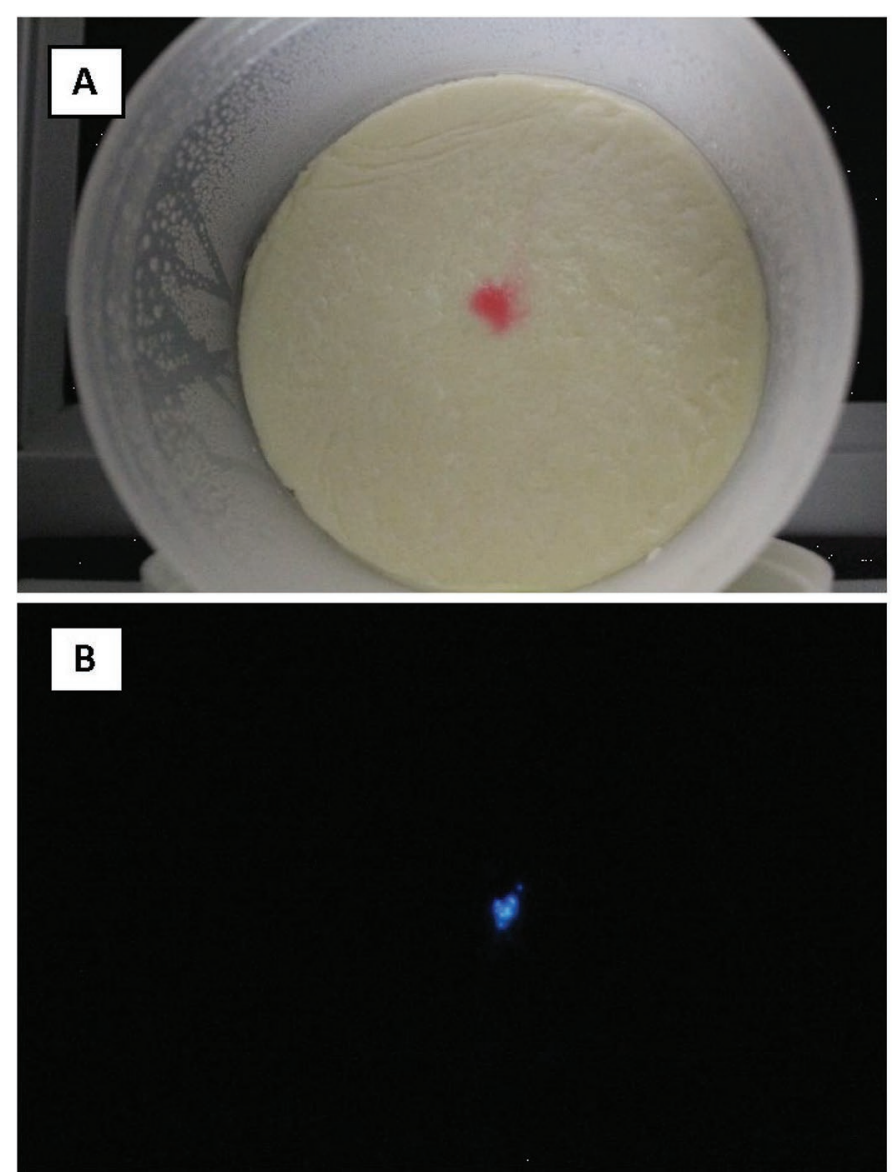

Figure 5. Commercial wheel of queso fresco inoculated with $1 \times$ $10^{3} \mathrm{cfu} / 10 \mu \mathrm{L}$ of Escherichia coli, with image taken in (A) normal lighting, and (B) a dark box with a long exposure time. The red spot indicates location of inoculum; cheese was not moved between capturing photographs. time-sensitive in nature, and relatively long incubation times are not ideal, this forensic tool is intended for use after a food has tested positive for a bacterial contaminant, when the source of contamination is being investigated. This tool can be used to potentially shorten the time needed to determine the source of contamination and ultimately reduce shutdown time and any further contamination of foods. In this work, we demonstrated 2 methods to use this phage-based tool. The first was surface application of phage, which allows easy use on any sample surface; for example, a set of cheeses purchased from the store or pulled from retail storage. The drawback of the surface-application method is that it cannot detect internalized cells unless samples are cut. The second method was incorporating the phage in the cheese matrix. We would not recommend the incorporation of bioengineered phage into regular production runs, only for special runs to troubleshoot contamination events. The benefit of direct incorporation is that it removes the challenge of applying a consistent overlay and can more readily detect internalized cells, although the sample would need to be cut open for visual inspection. For each defined application, phage specific to the target bacteria of interest will need to be engineered to produce NanoLuc or comparable, easily visualized reporters. Because of the specificity of phage, a cocktail of engineered phages may need to be developed. For addressing L. monocytogenes, specific phage(s) will need to be bioengineered to carry the NanoLuc reporter and evaluated for host range, sensitivity, and time to observable signal because variables such as host specificity, replication speed, and burst size will be different from our model T7-E. coli system. Phage represent powerful, customizable tools that can help improve food safety and our understanding of the bacterial populations located in our foods and environments.

\section{ACKNOWLEDGMENTS}

This material is based upon work supported by the National Institute of Food and Agriculture, US Department of Agriculture (Washington, DC; Hatch grant under 1014293). We thank the Nugen Research Group at Cornell University (Ithaca, NY) for providing the phage, imaging facilities, and guidance. The authors have not stated any conflicts of interest.

\section{REFERENCES}

Alcaine, S. D., K. Law, S. Ho, A. J. Kinchla, D. A. Sela, and S. R. Nugen. 2016. Bioengineering bacteriophages to enhance the sensitivity of phage amplification-based paper fluidic detection of bacteria. Biosens. Bioelectron. 82:14-19. https://doi.org/10.1016/ j.bios.2016.03.047. 
Arias-Rios, E. V., K. Tenney, T. Mai, S. Anderson, R. M. Cantera, J. M. Pando, B. Selover, L. M. Nadala, S. K. Davidson, and M. Samadpour. 2019. Application of an environmental phage-based assay (Sample6 Detect HT/L) for the detection of Listeria spp. in ice cream. J. AOAC Int. 102:1132-1137. https://doi.org/10.5740/ jaoacint.18-0253.

Dominguez, M., N. Jourdan-Da Silva, V. Vaillant, N. Pihier, C. Kermin, F.-X. Weill, G. Delmas, A. Kerouanton, A. Brisabois, and H. de Valk. 2009. Outbreak of Salmonella enterica serotype Montevideo infections in France linked to consumption of cheese made from raw milk. Foodborne Pathog. Dis. 6:121-128. https://doi .org/10.1089/fpd.2008.0086.

García, P., C. Madera, B. Martínez, and A. Rodríguez. 2007. Biocontrol of Staphylococcus aureus in curd manufacturing processes using bacteriophages. Int. Dairy J. 17:1232-1239. https://doi.org/ 10.1016/j.idairyj.2007.03.014.

Gaulin, C., E. Levac, D. Ramsay, R. Dion, J. Ismaill, S. Gingras, and C. Lacroix. 2012. Escherichia coli O157:H7 outbreak linked to raw milk cheese in Quebec, Canada: Use of exact probability calculation and case-case study approaches to foodborne outbreak investigation. J. Food Prot. 75:812-818. https://doi.org/10.4315/0362 -028X.JFP-11-385.

Hagens, S., and M. J. Loessner. 2007. Application of bacteriophages for detection and control of foodborne pathogens. Appl. Microbiol. Biotechnol. 76:513-519. https://doi.org/10.1007/s00253-007-1031 -8 .

Hall, M. P., J. Unch, B. F. Binkowski, M. P. Valley, B. L. Butler, M. G. Wood, P. Otto, K. Zimmerman, G. Vidugiris, T. Machleidt, M. B. Robers, H. A. Benink, C. T. Eggers, M. R. Slater, P. L. Meisenheimer, D. H. Klaubert, F. Fan, L. P. Encell, and K. V. Wood. 2012. Engineered luciferase reporter from a deep sea shrimp utilizing a novel imidazopyrazinone substrate. ACS Chem. Biol. 7:1848-1857. https://doi.org/10.1021/cb3002478.

Hinkley, T. C., S. Garing, S. Singh, A.-L. M. Le Ny, K. P. Nichols, J. E. Peters, J. N. Talbert, and S. R. Nugen. 2018. Reporter bacteriophage T7 NLC utilizes a novel NanoLuc:CBM fusion for the ultrasensitive detection of Escherichia coli in water. Analyst 143:4074-4082. https://doi.org/10.1039/c8an00781k.

Hitchens, A. D., K. Jinneman, and Y. Chen. 2017. Detection of Listeria monocytogenes in foods and environmental samples, and enumeration of Listeria monocytogenes in foods. BAM: Detection and Enumeration of Listeria monocytogenes. Accessed April 5, 2019. https: //www.fda.gov/Food/FoodScienceResearch/LaboratoryMethods/ ucm071400.htm.

Kropinski, A. M.. A. Mazzocco, T. E. Waddell, E. Lingohr, and R. P. Johnson. 2009. Enumeration of bacteriophages by double agar overlay plaque assay. Methods in Molecular Biology. M. R. J. Clokie and A. M. Kropinski, ed. Humana Press, Totowa, NJ.

Lawton, M. R., K. G. Jencarelli, S. M. Kozak, and S. D. Alcaine. 2020. Short communication: Evaluation of commercial meat cultures to inhibit Listeria monocytogenes in a fresh cheese laboratory model. J. Dairy Sci. 103:1269-1275. https://doi.org/10.3168/jds .2019-17203.

Lovett, J., D. W. Francis, and J. M. Hunt. 1987. Listeria monocytogenes in raw milk: Detection, incidence, and pathogenicity. J. Food Prot. 50:188-192. https://doi.org/10.4315/0362-028X-50.3.188.

Rosso, L., S. Bajard, J. P. Flandrois, C. Lahellec, J. Fournaud, and P. Veit. 1996. Differential growth of Listeria monocytogenes at 4 and $8^{\circ} \mathrm{C}$ : Consequences for the shelf life of chilled products. J. Food Prot. 59:944-949. https://doi.org/10.4315/0362-028X-59.9.944.

Tomat, D. D., L. Migliore, V. Aquili, A. Quiberoni, and C. Balagué. 2013. Phage biocontrol of enteropathogenic and shiga toxin-producing Escherichia coli in meat products. Front. Cell. Infect. Microbiol. 3. https://doi.org/10.3389/fcimb.2013.00020.

\section{ORCIDS}

Sarah Kozak @ https://orcid.org/0000-0003-2538-1463

Samuel D. Alcaine $\odot$ https://orcid.org/0000-0001-7953-9145 